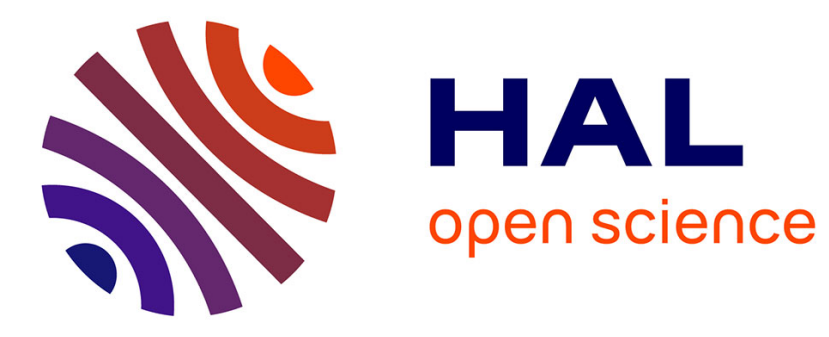

\title{
Phase-change materials to improve solar panel's performance
}

Pascal Henry Biwole, Pierre Eclachec, Frédéric Kuznik

\section{To cite this version:}

Pascal Henry Biwole, Pierre Eclachec, Frédéric Kuznik. Phase-change materials to improve solar panel's performance. Energy and Buildings, 2013, 62, pp.59-67. 10.1016/j.enbuild.2013.02.059 . hal00805269

HAL Id: hal-00805269

https://hal-mines-paristech.archives-ouvertes.fr/hal-00805269

Submitted on 11 Jun 2014

HAL is a multi-disciplinary open access archive for the deposit and dissemination of scientific research documents, whether they are published or not. The documents may come from teaching and research institutions in France or abroad, or from public or private research centers.
L'archive ouverte pluridisciplinaire HAL, est destinée au dépôt et à la diffusion de documents scientifiques de niveau recherche, publiés ou non, émanant des établissements d'enseignement et de recherche français ou étrangers, des laboratoires publics ou privés. 


\title{
Phase-change materials to improve solar panel's performance
}

\author{
Pascal Biwole ${ }^{1,2, *}$, Pierre Eclache ${ }^{3}$, Frederic Kuznik ${ }^{3}$ \\ ${ }^{1}$ University of Nice Sophia-Antipolis, J-A Dieudonné Laboratory,UMR CNRS 6621, 06108 Nice, France \\ ${ }^{2}$ MINES ParisTech, PERSEE - Center for Processes, Renewable Energies and Energy Systems, F-06 904 \\ Sophia Antipolis, France \\ ${ }^{3}$ Université de Lyon, \\ INSA-Lyon, CETHIL, CNRS, UMR5008, F-69621, Villeurbanne, France \\ Université Lyon 1, F-69622, France \\ * Corresponding author.Tel: +33 492965029,Fax:+33 492965071,E-mail:phbiwole@unice.fr
}

\begin{abstract}
High operating temperatures induce a loss of efficiency in solar photovoltaic and thermal panels. This paper investigates the use of phase-change materials (PCM) to maintain the temperature of the panels close to ambient. The main focus of the study is the computational fluid dynamics (CFD) modeling of heat and mass transfers in a system composed of an impure phase change material situated in the back of a solar panel (SP). A variation of the enthalpy method allows simulating the thermo-physical change of the material properties. The buoyancy term in Navier-Stokes' momentum conservation equation is modified through an additional term which forces the velocity field to be non-existent when the PCM is solid. For validation purposes, isotherms and velocity fields are calculated and compared to those from an experimental set-up. Results show that adding a PCM on the back of a solar panel can maintain the panel's operating temperature under $40^{\circ} \mathrm{C}$ for 80 minutes under a constant solar radiation of $1000 \mathrm{~W} / \mathrm{m}$.
\end{abstract}

Keywords: Solar Panel, Operating Temperature, Phase Change Material

\section{Nomenclature}

a thermal diffusivity

$\mathrm{m} \cdot \mathrm{s}^{-1}$

$\mathrm{B}_{0}$ melt function

$\mathrm{B}_{1}$ smoothed melt function

Cp specific heat

$\mathrm{J} \mathrm{kg}^{-1} \mathrm{~K}^{-1}$

D smoothed delta Dirac function

$F_{a}$ added buoyancy force

N.m ${ }^{-3}$ 


$\begin{array}{lll}\mathrm{F}_{\mathrm{b}} \quad \text { buoyancy force from Boussinesq approximation } & \mathrm{N} \cdot \mathrm{m}^{-3} \\ \mathrm{~g} \quad \text { gravitational constant } & \mathrm{m} \cdot \mathrm{s}^{-2} \\ \mathrm{~h}_{\mathrm{e}} \quad \text { outdoor convection heat transfer coefficient } & \mathrm{Wm}^{-2} \mathrm{~K}^{-1} \\ \mathrm{~h}_{\mathrm{i}} \quad \text { indoor convection heat transfer coefficient } & \mathrm{Wm}^{-2} \mathrm{~K}^{-1} \\ \mathrm{H} & \text { PCM container height } & \mathrm{m} \\ \mathrm{k} \quad \text { thermal conductivity } & \mathrm{W} \cdot \mathrm{m}^{-1} \mathrm{~K}^{-1} \\ \mathrm{l} \quad \text { characteristic length } & \mathrm{m} \\ \mathrm{L}_{\mathrm{F}} \quad \text { latent heat of fusion } & \mathrm{J} \mathrm{kg-1} \\ \mathrm{L} \quad \text { PCM container internal width } & \mathrm{m} \\ \mathrm{m} \quad \text { mass } & \mathrm{kg} \\ \mathrm{P} \quad \text { pressure } & \mathrm{Pa} \\ \mathrm{P}_{\mathrm{e}} & \text { mass Peclet number } & - \\ \mathrm{Ra} & \text { Rayleigh number } & \\ \mathrm{T} & \text { temperature } & \mathrm{K} \\ \mathrm{T}_{\mathrm{m}} \text { mean melt temperature } & \mathrm{K} \\ \mathrm{u} \quad \text { velocity } & \mathrm{m} \cdot \mathrm{s}^{-1} \\ \Delta \mathrm{T} \text { half range of melt temperatures } & \mathrm{K} \\ \Delta \mathrm{x} \text { maximum length of mesh cells } & \mathrm{m}\end{array}$

\section{Greek letters}

$\beta$ coefficient of thermal expansion $\quad \mathrm{K}^{-1}$

$\rho$ density $\quad \mathrm{kg} \cdot \mathrm{m}^{-3}$

$\mu$ dynamic viscosity Pa.s

$v$ kinematic viscosity $\quad \mathrm{m} \cdot \mathrm{s}^{-1}$

\section{Subscripts \\ liquid liquid phase \\ solid solid phase}

\section{Introduction}

The efficiency of solar panels depends on three factors: the intensity of the solar radiation flux, the quality of the semi conductor in use, and the operating temperature of the semi conductor cell. The variations of solar radiation cannot be controlled. Therefore, the ongoing 
research focuses either on new material like copper, indium diselenium, cadmium tellurium and chalcopyrites, or on maintaining low operating temperatures. For photovoltaic (PV) panels, high operating temperatures create a drop in the conversion rate of about $0.5 \%$ per Celsius degree over the nominal cell operating temperature of $25^{\circ} \mathrm{C}$ [1], as defined by the industry standard STC (Standard Test Conditions). In summer, panel's temperature typically ranges from 40 to $70^{\circ} \mathrm{C}$ which makes a 7.5 to $22.5 \%$ drop in the conversion rate. In the same way, the efficiency of solar thermal panels decreases mainly because of radiation losses when the operating fluid temperature is above ambient.

To lower the operating temperature, one can either improve the free cooling on the back of the panel using natural or forced convection, or try to absorb the excess heat by modifying the panel's architecture. The latter solution includes the use of PCMs situated on the back of solar panels. PCMs are materials that undergo reversible transition of phase depending on their temperature. They absorb or reject heat in the process. The numerical simulation of PCMs behavior has been extensively researched. Voller et al. [2] presented an enthalpy method for coupled convection and diffusion phase change. They later applied their technique to the melting of a pure metal [3]. Hu and Argylopoulos [4] made a review of the existing mathematical methods to model PCMs melting or solidification. Bertrand et al. [5] presented a model for PCM melting driven only by natural convection.

The specific use of PCMs for thermal energy storage (TES) was reviewed by Setterwall [6] and Zalba et al. [7]. In buildings, PCMs are being studied for free cooling or to enhance the building's thermal inertia. Research on this subject mainly deals with PCMs incorporated in wallboards [8] [9], roofs [10], windows [11], and ventilation heat exchangers [12]. A review on these applications can be found in Tyagi and Buddhi [13], Zhang et al. [14], and Raj and Velraj [15]. Regarding the materials used, paraffin waxes are very good candidates as PCMs for TES applications in buildings because of their low temperature of melting and their high heat of fusion. Rubitherm GmBH [16] technically graded the paraffin wax RT25 by the use of thermo sensors and differential scanning calorimetry analysis.

Only a few studies have been specifically devoted to passive cooling of solar panels by SP/PCM architectures. The hypothesis driving the research is simple: when the panel's temperature rises, the excess heat must be absorbed until the PCM has completely melted. When the panel's temperature decreases, the solidification of the PCM should provide 
additional heat for the operating liquid in solar thermal panels, provide heat to the building or act as an insulation material. The SP/PCM solution is expected to be very useful for roof or facade integrated panels where space for ventilation is limited.

Huang et al. [17] studied the melting of PCMs in an aluminum container submitted to a solar radiation of 750 to $1000 \mathrm{~W} / \mathrm{m}$. They used a finite volume model to analyze both the heat transfer diffusion and the Navier-Stokes equations. They later included cooling fins in the tank to improve the PCM bulk thermal conductivity [18] [19]. They found that the temperature rise in the system could be reduced by more than $30^{\circ} \mathrm{C}$ for 130 minutes. Cellura et al. [20] analyzed the same architecture using a finite element partial differential equation (PDE) solver. However, they considered the PCM as pure, meaning that the PCM melting temperature is unique and does not change while the PCM is still melting. This property is not valid for most commercial PCMs which are generally mixtures of several different materials. By analyzing only the heat transfer diffusion equation, they showed that a PCM with a melting temperature between $28^{\circ} \mathrm{C}$ and $32^{\circ} \mathrm{C}$ can improve the energy conversion efficiency by around $20 \%$ in summer time. Jay et al. [21] experimentally studied a layout where PCM were contained in a honeycomb grid to improve conduction in the container. They showed that after 6 hours and 30 minutes of testing under an artificial insulation of $800 \mathrm{~W} / \mathrm{m}$ on real PV panels, the temperature of a PV/PCM system was still lower than that of a single panel, with a mean temperature difference of $24^{\circ} \mathrm{C}$. They also found that the panel's temperature drop using a PCM with a melt temperature at $27^{\circ} \mathrm{C}$ was higher than using a $\mathrm{PCM}$ with a melt temperature at $45^{\circ} \mathrm{C}$.

In this study, we consider the same geometry and same PCM as [17], except for the experimental validation. The transient conduction and convection heat transfer as well as the Navier-Stokes equations are simultaneously resolved in the PCM domain using a finite element model on a fixed grid. The buoyancy term in Navier-Stokes' momentum conservation equation is modified through an additional term to force the velocity field to be zero when the PCM is solid. This scheme is validated using an experimental set-up. The model is then used for a parametric study of the SP/PCM architecture performances. 


\section{Methodology}

\subsection{Numerical case description}

The geometry of the model is presented in Fig. 1. The aluminum plate and fin widths are $4 \mathrm{~mm}$. The thermo-physical properties of the simulated materials are presented in Table 1. The thermal boundary conditions are as follows: On the left plate, an inward heat flux $\mathrm{E}=$ $1000 \mathrm{~W} / \mathrm{m}$ is applied to mimic solar radiation. The same plate also receives a convection heat flux due to the difference between the plate temperature and the external air temperature which is imposed as $T_{e}=20^{\circ} \mathrm{C}$. The value of the outdoor convection heat transfer coefficient is $h_{e}=10 \mathrm{~W} / \mathrm{m}$.K. Similarly, a convection heat flux is applied on the right aluminum plate with $\mathrm{T}_{\mathrm{i}}=\mathrm{T}_{\mathrm{e}}=20^{\circ} \mathrm{C}$ and $\mathrm{h}_{\mathrm{i}}=5 \mathrm{~W} / \mathrm{m}$.K. A symmetry boundary condition is applied on the top and bottom sides of the model.

A no slip boundary condition is applied on all internal surfaces of the PCM container.

\subsection{Mathematical model}

\subsubsection{Modeling heat transfers}

Over the front plate surface, we considered conduction, convection and radiation heat transfers as shown in Eq. (1). Long wave radiation with the sky was neglected in the model.

$\rho C_{p} \frac{\partial T}{\partial t}=-k \frac{\partial T}{\partial x}+h_{e}\left(T_{e}-T\right)+\alpha E(t)$

where $\alpha$ is the aluminum thermal absorptivity and $\mathrm{E}$ the solar radiation intensity. The heat transfers diffusion equation applies over the PCM, the air layer and the aluminum domains:

$\rho C_{p} \frac{\partial T}{\partial t}+\nabla \cdot(-k \nabla T)+\rho C_{p} \vec{u} . \nabla T=0$

The velocity field $\boldsymbol{u}$ in Eq. (2) is given by Navier-Stokes equations for incompressible fluids. To model the changes in PCM RT25 thermo-physical properties occurring during the phase transition, we define function $\mathrm{B}_{0}$ as the liquid fraction in the PCM domain. Let $\mathrm{T}_{\mathrm{m}}$ be the mean melt temperature and $\Delta \mathrm{T}$ the half range of melt temperatures: 
$B_{0}(T)=\left\{\begin{array}{ccc}0 & , & T<\left(T_{m}-\Delta T\right) \\ \left(T-T_{m}+\Delta T\right) /(2 \Delta T) & , & \left(T_{m}-\Delta T\right) \leq T<\left(T_{m}+\Delta T\right) \\ 1 & , & T>\left(T_{m}+\Delta T\right)\end{array}\right.$

Eqs. (3) show that $\mathrm{B}_{0}$ is zero when the PCM is in solid and 1 when it is in liquid phase. $\mathrm{B}_{0}$ linearly grows from zero to 1 between the two states. To ensure second order continuous differentiability of the liquid fraction over the temperature domain, $\mathrm{B}_{0}(\mathrm{~T})$ is approximated by a second order differentiable function $\mathrm{B}_{1} \cdot \mathrm{B}_{1}(\mathrm{~T})$ is the sixth-degree polynomial whose seven coefficients are calculated using the following conditions:

$\left\{\begin{array}{lllll}B_{1}\left(T_{m}-\Delta T\right)=0 & ; & B_{1}^{\prime}\left(T_{m}-\Delta T\right)=0 & ; & B^{\prime \prime}{ }_{1}\left(T_{m}-\Delta T\right)=0 \\ B_{1}\left(T_{m}+\Delta T\right)=1 & ; & B^{\prime}{ }_{1}\left(T_{m}+\Delta T\right)=0 & ; & B^{\prime \prime}{ }_{1}\left(T_{m}+\Delta T\right)=0\end{array}\right.$

where $\mathrm{B}_{1}$ ' and $\mathrm{B}_{1}$ " are $\mathrm{B}_{1}(\mathrm{~T})$ first and second derivatives. Function $\mathrm{B}_{1}(\mathrm{~T})$ yields the same values as function $B_{0}(T)$. The only difference is that $B_{1}$ is a second order continuously differentiable function. This scheme helps numerical convergence. $\mathrm{B}_{1}$ is used to model the changes in the PCM thermo physical properties as follows:

$$
\begin{aligned}
& \rho(T)=\rho_{\text {solid }}+\left(\rho_{\text {liquid }}-\rho_{\text {solid }}\right) \cdot B_{1}(T) \\
& k(T)=k_{\text {solid }}+\left(k_{\text {liquid }}-k_{\text {solid }}\right) \cdot B_{1}(T)
\end{aligned}
$$

where $\rho$ is the density and $\mathrm{k}$ the thermal conductivity of the PCM. The modeling of the specific heat includes an additional term representing the latent heat of fusion absorbed during the melting process:

$$
C_{p}(T)=C_{p_{\text {solid }}}+\left(C_{p_{\text {liquid }}}-C_{p_{\text {solid }}}\right) \cdot B_{1}(T)+L_{F} \cdot D(T)
$$

where

$$
D(T)=e^{\frac{-T\left(T-T_{m}\right)^{2}}{\Delta T^{2}}} / \sqrt{\pi \cdot \Delta T^{2}}
$$


Function D is a smoothed Delta Dirac function which is zero everywhere except in interval $\left[\mathrm{T}_{\mathrm{m}}-\Delta \mathrm{T}, \mathrm{T}_{\mathrm{m}}+\Delta \mathrm{T}\right]$. It is centered on $\mathrm{T}_{\mathrm{m}}$ and its integral is 1 . Its main role is to distribute the latent heat equally around the mean melting point.

\subsubsection{Modeling of mass and momentum transfers for PCM domain}

We assumed that the PCM in the liquid phase is a Newtonian fluid. The mass, momentum and energy conservation equations were resolved simultaneously with the heat transfer diffusion equation. However, to model the phase transition, the momentum conservation equation was modified as follows:

$\rho \frac{\partial \vec{u}}{\partial t}+\rho(\vec{u} . \nabla) \vec{u}-\mu . \nabla^{2} \vec{u}=-\nabla P+\vec{F}_{b}+\vec{F}_{a}$

where $\mathbf{F}_{\mathbf{b}}$ is buoyancy force given by the Boussinesq approximation:

$\vec{F}_{b}=-\rho_{\text {liquid }}\left(1-\beta\left(T-T_{m}\right)\right) \vec{g}$

and

$\vec{F}_{a}=-A(T) \cdot \vec{u}$

with the expression of $A(T)$ inspired from the Carman-Koseny relation in a porous medium and the expression of $\nabla(P)$ from the Darcy's law as presented in [23] and [24]:

$$
A(T)=\frac{C\left(1-B_{1}(T)\right)^{2}}{\left(B_{1}(T)^{3}+q\right)}
$$

If we assume that the flow is laminar:

$$
\nabla(P)=\frac{-C\left(1-B_{1}(T)\right)^{2}}{B_{1}(T)^{3}} \cdot \vec{u}
$$

The value of $\mathrm{C}$ depends on the morphology of the medium. In this study, $\mathrm{C}$ is given the constant value $10^{5}$. This value is chosen arbitrarily high. Constant q is chosen very low in 
order to make Eq. (12) valid even when $B_{1}(T)$ is zero. The value of q was fixed at $10^{-3}$. When the temperature of the PCM is higher than $\mathrm{T}_{\mathrm{m}}+\Delta \mathrm{T}$, the PCM is completely liquid. Therefore, $\mathrm{B}_{1}$ is 1 and consequently $\mathrm{A}$ and $\mathbf{F}_{\mathbf{a}}$ are zero. In this case, the usual momentum conservation equation applies. During the transition state, $0<\mathrm{B}_{1}(\mathrm{~T})<1$. $\mathrm{A}(\mathrm{T})$ increases along with the melting process until the added force $\mathbf{F}_{\mathbf{a}}$ becomes greater than the convection and diffusion terms in Eq. (9). The momentum conservation equation becomes similar to the Darcy law for fluid flow in porous medium:

$\vec{u}=-\frac{K}{\mu} \nabla(P)$

where the permeability $K$ is a function of $B_{1}(T)$. When $B_{1}(T)$ diminishes, the velocity field also diminishes until it reaches zero when the PCM becomes completely solid. At that point, the PCM temperature is lower than $T_{m}-\Delta T$. Therefore, $B_{1}$ is 0 . Eq. (12) shows that the value of $\mathrm{A}(\mathrm{T})$ becomes very high. Consequently, all the terms in the momentum conservation equation are dominated by the added force. The only solution of the Navier-Stokes equations is $\mathbf{u}=\mathbf{0}$ which corresponds to a solid medium.

\subsubsection{Numerical method}

A 2D finite element model was used. The temperature and pressure field were approximated using 2D linear Lagrangian elements with three degrees of freedom:

$$
\begin{aligned}
& T=\sum_{i=1}^{3} N_{i} T_{i} \\
& P=\sum_{i=1}^{3} N_{i} P_{i}
\end{aligned}
$$

To satisfy the Brezzi-Babuska condition [22] an additional degree of freedom was used by adding a node at the center of mass of each triangular element to approximate the velocity field as shown in Eq. (17) and Fig. 2.

$$
\vec{u}=\sum_{i=1}^{3} N_{i} \vec{u}_{i}+N_{b} \vec{u}_{b}
$$


Since the use of standard Galerkin mesh might create numerical instability when the convection term dominates the diffusion term in Eq. (9), the maximum mesh size was defined using a condition on the mass mesh Peclet number:

$$
P e=\frac{u \Delta x}{v}<2
$$

where $\Delta \mathrm{x}$ is the maximum length of mesh cell in a unit 2D surface. The maximum velocity in the PCM tank was experimentally determined at $10^{-2} \mathrm{~m} / \mathrm{s}$. Therefore, Eq. (18) gives $\Delta \mathrm{x} \approx 5 \mathrm{e}-$ $4 \mathrm{~m}, P e$ was kept lower than 1 . Consequently, the maximum mesh size was $4.10 \mathrm{e}-4 \mathrm{~m}$. The mesh was refined at the borders of the PCM domain (see Fig. 3). The final mesh had 135240 elements and 465857 degrees of freedom. No significant change of the results was observed when using a finer mesh. A Galerkin least-squares stabilization method was employed.

\subsection{Elements of validation}

As shown in Fig. 4, the experimental set-up consisted of a Plexiglas container without cooling fins and filled with a PCM whose thermo-physical properties are listed in Table 2. An air layer was left at the top of the tank to prevent it from breaking due to the PCM thermal expansion. A fixed temperature was imposed on each side of the tank using heating plates. The uncertainty in the applied temperature by heating plates was $\pm 0.4^{\circ} \mathrm{C}$. The inner cavity containing the PCM was $167 \mathrm{~mm} \times 167 \mathrm{~mm} \times 30 \mathrm{~mm}$-large. The transient two-dimensional velocity field in the cavity was measured through a particle image velocimetry (PIV) apparatus which included a Nd-Yag laser. The uncertainty of the PIV velocity measurement was $\pm 2 \mathrm{~mm} / \mathrm{s}$.

There were two different experimental comparisons: firstly, a transient comparison of the simulated and actual liquid-solid moving boundary location was carried out. On this first experiment, a fixed temperature of $40^{\circ} \mathrm{C}$ was imposed on the left side of the PCM tank and $20^{\circ} \mathrm{C}$ was imposed on the right side. A photograph of the boundary was taken every 20 minutes. This first comparison showed a good agreement between simulation and measurement except on the top of the PCM domain as visible in Fig. 5. The difference here is probably due to the air layer which was not simulated. On top of the simulated model, an adiabatic and a no slip boundary condition were used as presented in Fig.1. 
Secondly, a stationary comparison of the simulated and measured two dimensional velocity fields in the completely melted PCM on the four cross-sections is shown in Fig. 6. For this second experiment, a fixed temperature of $38^{\circ} \mathrm{C}$ was imposed on the left side of the PCM tank and $28^{\circ} \mathrm{C}$ was imposed on the right side.

As shown in Figs. 7 and 8, the magnitude of velocity on the left side, upper side and bottom side of the system is of the order of $0.001 \mathrm{~m} / \mathrm{s}$ to $0.002 \mathrm{~m} / \mathrm{s}$ while on the right side, which is the colder side of the system, the velocity magnitude is around $0.005 \mathrm{~m} / \mathrm{s}$. This observed unbalanced velocity field was not reproduced by the numerical model which keeps a perfect balance due to the mass and momentum conservation equations. The simulated velocity always exceeded the experimental one. The discrepancy was of the order of $4 \mathrm{~mm} / \mathrm{s}$ on the front plate and $2 \mathrm{~mm} / \mathrm{s}$ on the back plate. It should be noted that the measured velocity was close to the uncertainty of the PIV measurement.

\section{Results and discussion}

The numerical model presented in Fig. 1 was used to carry out a parametric study. All the simulations were conducted using $\mathrm{T}_{\mathrm{e}}=\mathrm{T}_{\mathrm{i}}=20^{\circ} \mathrm{C}, \mathrm{h}_{\mathrm{e}}=10 \mathrm{~W} / \mathrm{m} . \mathrm{K}, \mathrm{h}_{\mathrm{i}}=5 \mathrm{~W} / \mathrm{m} . \mathrm{K}$ and $\mathrm{E}=$ $1000 \mathrm{~W} / \mathrm{m}$ and $\Delta \mathrm{T}=0.5 \mathrm{~K}$. The different cases simulated during the parametric study are presented in Table 3.

\subsection{SP/PCM system without cooling fins}

The simulated temperature and velocity fields in the SP/PCM system (e) without cooling fins at different instant times are presented in Figs. 9 and 10. The melted PCM goes upward close to the heated aluminum plates, and downward along the solid PCM which is blue colored. The melting process gets accelerated after 40min when the melted PCM touches the back plate because it gets warmer than the melt temperature. Then the remaining solid PCM is progressively separated from the back plate and another upward flow is observed from the bottom of the back plate to the top of the still solid PCM. The PCM is completely melted after 104 minutes. At this time, the mean temperature of the front plate is $48^{\circ} \mathrm{C}$. Afterwards its temperature rises more quickly. As shown on Fig. 10, the mean velocity of the liquid PCM is $7.3 \mathrm{e}-03 \mathrm{~m} / \mathrm{s}$ on the front plate, $3.5 \mathrm{e}-03 \mathrm{~m} / \mathrm{s}$ on the solid PCM surface, and $1.8 \mathrm{e}-03 \mathrm{~m} / \mathrm{s}$ on the back plate. 
The Rayleigh number in the liquid PCM was calculated as:

$R a=\frac{g \beta\left(T_{\text {plate }}-T_{\text {liquid }}\right) \cdot H^{3}}{v \cdot a}$

where $T_{\text {plate }}$ is the temperature of the left (heated) plate, $T_{\text {liquid }}$ is the mean temperature of the liquid PCM and $a$ its thermal diffusivity. The value of Ra was found equal to $9.5 \mathrm{e} 06$ at melt start and $4.8 \mathrm{e} 07$ at melt end. This result is coherent with our initial assumption of a laminar flow and confirms the observation of [4].

\subsection{SP/PCM system with cooling fins}

The simulated temperature and velocity fields in the SP/PCM system (c) with cooling fins at different instants of time are presented in Figs. 11 and 12. There is a circulation of the liquid PCM through the three parts of the container. Convection of the liquid PCM is observed upward close to the heated panel, and downward close to the liquid-solid boundary through the space between the fins and the back plate. As shown on Fig. 12, the PCM velocity close to the front plate increases with time. The velocity is $40 \mathrm{e}-03 \mathrm{~m} / \mathrm{s}$ when the PCM is completely melted with a mean value of $18 \mathrm{e}-03 \mathrm{~m} / \mathrm{s}$ during the melting process.

The Rayleigh number in the liquid PCM was calculated as:

$R a=\frac{g \beta\left(T_{\text {plate }}-T_{\text {liquid }}\right) \cdot l^{3}}{v \cdot a}$

where the characteristic length $l$ was taken as the height of each section of the PCM tank which is $0.04 \mathrm{~m}$ at the middle section and $0.042 \mathrm{~m}$ at the bottom and upper sections. The value of Ra was calculated as $5 \mathrm{e} 06$ at melt start and $5.3 \mathrm{e} 07$ at melt end. In spite of these medium Rayleigh numbers, the velocity streamlines plotted on Fig. 11 suggest that the flow in each section of the tank is weakly turbulent. Like [4], we also numerically observe a suspended solid PCM mass when the melting is nearly over. This is due to the mechanical resistance created by the fin and the liquid PCM under the solid mass.

\subsection{Parametric study of the front plate temperature}

The transient temperature of the front plate was simulated for different sizes and shapes of the PCM container and compared to the temperature of a single aluminum plate - which is case (a) - under the same boundary conditions. The result is shown on Fig 13.

Three inflexions points can be observed on the transient operating temperature profile for cases (c), (d) and (e). The first one happens at the PCM melt temperature. After a steep 
increase, the panel temperature rises much more slowly from that point on because of the start of the melting process.

Between the first and the second inflexion point, the PCM acts like an insulation material for the panel and heat transfer is dominated by conduction. The second inflexion point indicates the start of the convection heat transfer which balances conduction heat transfer in the PCM. The operating temperature remains more or less constant until the PCM has completely melted. The graph for case (b) shows that the simulated panel temperature may be overestimated by more than $20 \%$ after 3600 seconds when conduction only is considered in the numerical model.

The last inflexion point marks the end of the melting process. Heat transfer in the container is dominated by convection. Afterwards the temperature rises with a smaller slope than at the beginning of the process when the PCM was completely solid. This is due to the higher specific heat capacity of the liquid PCM in comparison with the specific heat capacity of the solid PCM. Nevertheless, the front plate temperature quickly rises towards its maximum since heat is no longer absorbed by the solid PCM.

Over the range of simulated sizes for the SP/PCM system, the temperature of the front plate always remains lower than $50^{\circ} \mathrm{C}$ after 89 minutes under a constant radiation of $1000 \mathrm{~W} / \mathrm{m}^{2}$. The better performance is obtained with a $13.2 \times 4.9 \mathrm{~cm}$ large PCM container featuring $3 \mathrm{~cm}$ long fins. In this case, the panel's temperature is $34.9^{\circ} \mathrm{C}$ after 1 hour. The same temperature is reached after 5 minutes without PCM as shown on Fig. 13. These observations are in good agreement with [3] and [5]. The predicted percentages temperature drop of the front plate with respect to the PCM container shape and time are listed in Table 4.

As expected, the parametric study also showed that the operating temperature drops proportionally to the increase of the PCM width: after 3600 seconds, $\mathrm{T}=34.9^{\circ} \mathrm{C}$ when $\mathrm{L}=$ $0.049 \mathrm{~m}$ whereas $\mathrm{T}=37^{\circ} \mathrm{C}$ when $\mathrm{L}=0.02 \mathrm{~m}$. Comparing graphs (d) and (e) shows that the same trend is observed when the panel height is increased but only when the PCM has completely melted. In brief, it is better to increase the PCM width than its height to lower the panel's temperature. Adding cooling fins in the PCM tank provides a faster attenuation of the operating temperature because the PCM bulk conductivity is increased. But this layout accelerates the phase transition too, as shown on Figs. 9, 11 and 13. When the PCM has completely melted, the operating temperature rises faster than for all other SP/PCM 
architectures (Fig. 13). This fact mitigates the idea that adding cooling fins makes SP/PCM systems more efficient [4].

\section{Conclusion}

In this work, we proposed a detailed mathematical and numerical modeling of heat and mass transfers in coupled solar panel/phase change material architectures. A volume force was added to the buoyancy term in the Navier-Stokes' momentum conservation equation in order to force the velocity field to be zero when the PCM is solid. In order to simulate both conduction and convection, the transient heat transfer diffusion equation was numerically solved simultaneously with the Navier-Stokes equations using a finite elements method.

To validate the model, the experimental and simulated moving solid-liquid boundary was compared as well as the velocity field inside the PCM container through a PIV apparatus. Then a parametric study was performed on the temperature of the panel represented by a flat aluminum plate with the purpose of predicting the efficiency of SP/PCM architectures.

The simulated SP/PCM systems allowed maintaining the panel's temperature under $40^{\circ} \mathrm{C}$ during 80 minutes of constant exposure to a radiation of $1000 \mathrm{~W} / \mathrm{m}$. The same temperature was reached by the panel after only 5 minutes without the PCM.

One of the limitations of our study arises from the representation of the solar panel by an aluminum plate. This simplification fails to take into account the bulk specific capacity of real panels. The second limitation comes from the fact that the impact of sky temperature was not included in the numerical model, due to experimental validation difficulties. Despite these limitations, the observed results remain relevant. Future work should include experimental validations of this first numerical model using real solar panels under real climate conditions.

\section{References}

[1] K. Emery, J. Burdick, Y. Caiyem, D. Dunlavy, H. Field, B. Kroposki, T. Moriatry, Temperature dependence of photovoltaic cells, modules and systems, Proceedings of the 25th IEEE PV Specialists Conference, Washington DC, USA, May 13-19, 1996, pp. $1275-1278$. 
[2] V.R. Voller, M. Cross, N.C. Markatos, An enthalpy method for convection/diffusion phase change, International journal for numerical methods in engineering 24 (1) (1987), pp. 271-284.

[3] A.D. Brent, V.R. Voller and K.J. Reid, Enthalpy-Porosity Technique for Modelling Convection-Diffusion Phase Change: Application to the Melting of a Pure Metal, Numerical Heat Transfer 13 (3) (1988), pp. 297 - 318.

[4] H. Hu and S.A. Argylopoulos, Mathematical modelling of solidification and melting: a review, Modelling Simul. Mater. Sci. Eng. 4 (1996), pp. 371-396.

[5] O. Bertrand, B. Binet, H. Combeau, S. Couturier, Y. Delannoy, D. Gobin, M. Lacroix, P. Le Quéré, M. Médale, J. Mencinger, H. Sadat, G. Vieira, Melting driven by natural convection, a comparison exercise: first results, Int. J. Therm. Sci. 38 (1999), pp. 5-26

[6] F. Setterwall, Phase change materials and chemical reactions for thermal energy storage state of the art. In: Proceedings of the Seventh International Conference on Thermal Energy Storage, Tokyo, Japan, (1996), p. 1021.

[7] B. Zalba, J.M. Marin, F. Cabeza, Review on thermal energy storage with phase change: materials, heat transfer analysis and applications, Applied Thermal Engineering 23 (2003), pp. 251-283.

[8] K. Peippo, P. Kauranen, P.D. Lund, A multi component PCM wall optimized for passive solar heating, Energy \& Buildings 17 (1991), pp. 259-70.

[9] D.W. Hawes, D. Feldman, D. Banu, Latent heat storage in building materials, Energy Building 20 (1993), pp. 77-86.

[10] A. Pasupathy, R. Velraj, R.V. Seeniraj, Effect of double layered phase change materials in building roof for year round thermal management. Energy and Building 40(3) (2008), pp. 193-203.

[11] K. A. R. Ismail' and J. R. Henríquez, Thermally effective windows with moving phase change material curtains, Applied Thermal Engineering 21 (18) (2001), pp. 1909-1923

[12] Arkar and Medved 2007 Arkar C, Medved S. Free cooling of building using PCM heat storage integrated into the ventilation system. Solar Energy 2007; 81:1078-87.

[13] V.V. Tyagi, D. Buddhi, PCM thermal storage in buildings: a state of art. Renewable and Sustainable Energy Reviews 11 (6) (2007), pp. 1146-66. 
[14] Y. Zhang, G. Zhou, K. Lin, Q. Zhang, H. Di, Application of latent heat thermal energy storage in buildings: state-of-the-art and outlook. Building and Environment 42 (2) (2007), pp. 197-209.

[15] V.A.A. Raj, R. Velraj, Review on free cooling of buildings using phase change materials, Renewable and Sustainable Energy Reviews 14 (2010), pp. 2819-2829.

[16] Rubitherm GmbH, 2000. Rubitherm Data Sheet. Rubitherm GmbH, Hamburg.

[17] M.J. Huang, P.C. Eames, B. Norton, Thermal regulation of building integrated photovoltaics using phase change materials, International Journal of Heat and Mass Transfers 47, 2004, pp. 275-2733.

[18] M.J. Huang, P.C. Eames, B. Norton, Phase change materials for limiting temperature rise in building integrated photovoltaics, Solar Energy 80 (9), 2006, pp. 1121-1130.

[19] M.J. Huang, P.C. Eames, B. Norton, Comparison of a small-scale 3D PCM thermal control model with a validated 2D PCM thermal control model, Solar Energy Materials and Solar Cells 90 (13), 2006, pp. 1961-1972.

[20] M. Cellura, G. Ciulla, V. Lo Brano, A. Marvuglia, A. Orioli, Photovoltaic panel coupled with a phase changing material heat storage system in hot climates. In: Proceedings of the 25th Conference on Passive and Low Energy Architecture, Dublin, Ireland, October 22-24, 2008.

[21] A. Jay, S. Clerc, B. Boillot, A. Bontemps, F. Jay, Utilisation de matériaux à changement de phase pour réduire la température de panneaux PV intégrés au bâti, Proceedings of the International Building Performance Simulation Association conference, Moret sur Loing, France, November 9-10, 2010.

[22] D. N. Arnold, F. Brezzi, M. Fortin, A stable element for the Stokes equations, Calcolo ISSN: 0008-0624 (Print) 1126-5434 (Online), 21 (4), 1984, pp. 337-344.

[23] V.R.Voller, C.Prakash, A fixed grid numerical modeling methodology for convection diffusion mushy region phase-change problems, International Journal of Heat and Mass transfer (30), 1987, pp. 1709-1719.

[24] A. D. Brent, V. R. Voller, and K. J. Reid. Enthalpy-porosity technique for modeling convection-diffusion phase change: Application to the melting of a pure metal. Numerical Heat Transfer, 13(3), 1988, pp. 297-318. 
Figures captions:

Fig. 1. Main elements of the numerical model.

Fig. 2. 2D finite elements used.

Fig. 3. Mesh at a mid-height cross section of the numerical model.

Fig. 4. Experimental apparatus: (1) phase change material, (2) heat exchangers, (3) PCM intake valve, (4) structure system, (5) flow meter, (6) air intake valve, (7) metal stand, (8) insulation material.

Fig. 5. Transient comparison of the simulated and actual liquid-solid moving boundary location.

Fig. 6. Cross-sections for the comparison of measured and simulated velocity.

Fig. 7. Comparison of the PIV-measured and simulated velocity on horizontal cross-sections (1), (2), (3) and (4).

Fig. 8. PIV-measured 2D velocity field in the PCM tank.

Fig. 9. Simulated transient isotherms and velocity fields in the SP/PCM system without cooling fins. $\mathrm{H}=132 \mathrm{~mm}, \mathrm{~L}=20 \mathrm{~mm}$.

Fig. 10. Predicted vertical velocity at mid-height horizontal cross-section at the same time instants as in Fig. 9

Fig. 11. Simulated transient isotherms and velocity fields and streamlines in the SP/PCM system with cooling fins.

Fig. 12. Predicted vertical velocity at mid-height horizontal cross-section at the same time instants as in Fig.11.

Fig. 13. Impact of the SP/PCM size on the panel's operating temperature. 


\begin{tabular}{cccc}
\hline & $\mathrm{Cp}$ & $\mathrm{k}$ & $\rho$ \\
\hline Solid RT25 & 1800 & 0.19 & 785 \\
Liquid RT25 & 2400 & 0.18 & 749 \\
Aluminum & 903 & 211 & 2675 \\
Constant properties of RT25: \\
$\mathrm{L}_{\mathrm{F}}: 232000 \mathrm{~J} \mathrm{~kg}^{-1}$ \\
$\mathrm{~T}_{\mathbf{m}}: 26.6^{\circ} \mathrm{C}$ \\
$\beta: 1 \mathrm{e}-3 \mathrm{~K}^{-1}$ \\
$\mu: 1.7976 \mathrm{e}-3 \mathrm{~m}^{2} . \mathrm{s}^{-1}$ \\
\hline
\end{tabular}

Table 1. Thermo-physical properties of RT25 [16] and aluminum.

\begin{tabular}{|c|c|}
\hline$\rho_{\text {solid }}=\rho_{\text {liquid }}$ & $890\left[\mathrm{~kg} \cdot \mathrm{m}^{-3}\right]$ \\
\hline $\mathrm{C}_{\text {psolid }}=\mathrm{C}_{\text {liquid }}$ & $2110\left[\mathrm{~J} \mathrm{~kg}^{-1} \mathrm{~K}^{-1}\right]$ \\
\hline $\mathrm{L}_{\mathrm{F}}$ & $1.81 \times 10^{5}\left[\mathrm{~J} \mathrm{~kg}^{-1}\right]$ \\
\hline$v$ & $1.1 \times 10^{-5}\left[\mathrm{~m} \cdot \mathrm{s}^{-1}\right]$ \\
\hline$\beta$ & $3.09 \times 10^{-3}\left[\mathrm{~K}^{-1}\right]$ \\
\hline $\mathrm{k}_{\text {solid }}=\mathrm{k}_{\text {liquid }}$ & $0.182\left[\mathrm{~W} \cdot \mathrm{m}^{-1} \mathrm{~K}^{-1}\right]$ \\
\hline $\mathrm{g}$ & $9.81\left[\mathrm{~m} \cdot \mathrm{s}^{-2}\right]$ \\
\hline $\mathrm{T}_{\mathrm{m}}$ & $25\left[{ }^{\circ} \mathrm{C}\right]$ \\
\hline
\end{tabular}

Table 2. Thermo-physical properties of the PCM used for validation.

\begin{tabular}{cccccc}
\hline & (a) & (b) & (c) & (d) & (e) \\
\hline L(mm) & 0 & 20 & 20 & 20 & 20 \\
H(mm) & 132 & 132 & 132 & 40 & 132 \\
Cooling fins & no & no & yes & no & no \\
PCM convection simulated & no & no & yes & yes & yes \\
\hline
\end{tabular}

Table 3. List of simulated cases.

\begin{tabular}{cccc}
\hline & (c) & (d) & (e) \\
\hline After 1h & $56.9 \%$ & $57.2 \%$ & $55 \%$ \\
After 2h & $21 \%$ & $33.3 \%$ & $36.6 \%$ \\
After 3h & $0 \%$ & $12.6 \%$ & $16.6 \%$ \\
\hline
\end{tabular}

Table 4. Drop percentage of the panel's external temperature with respect to time and PCM layout by comparison with case (a). 
Figure 1

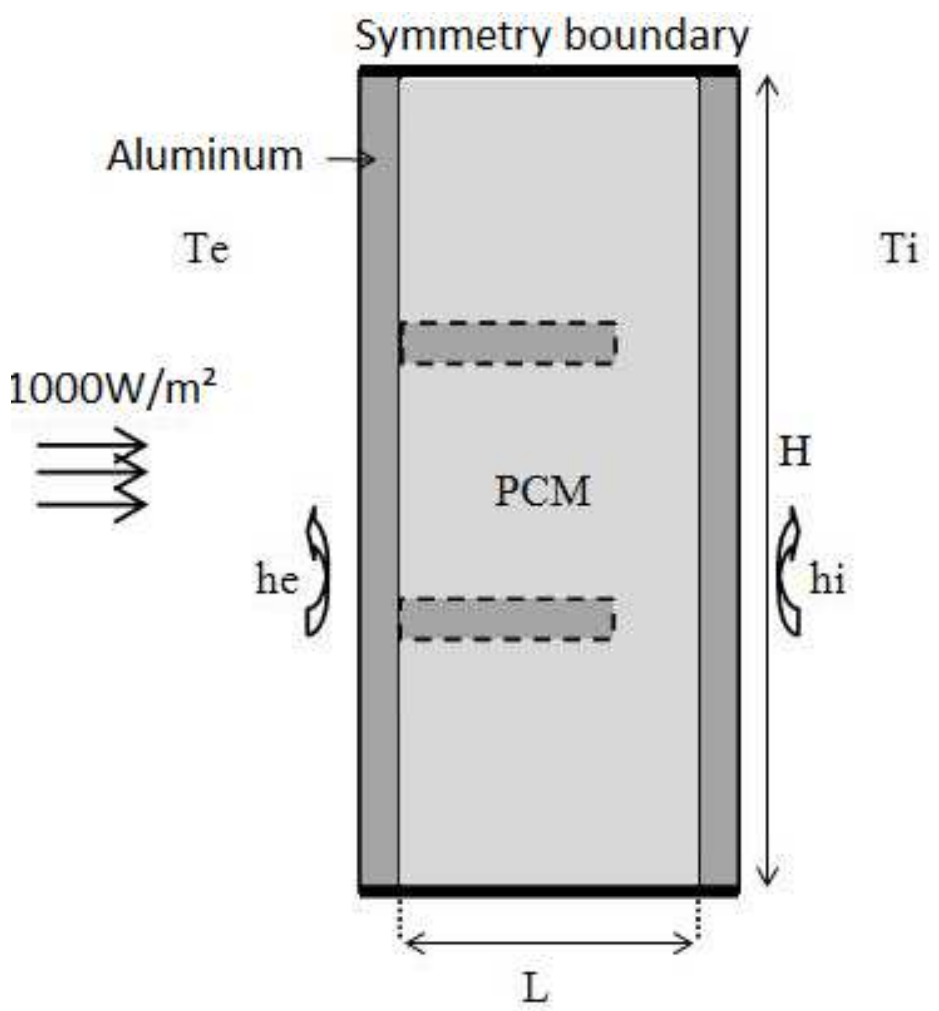




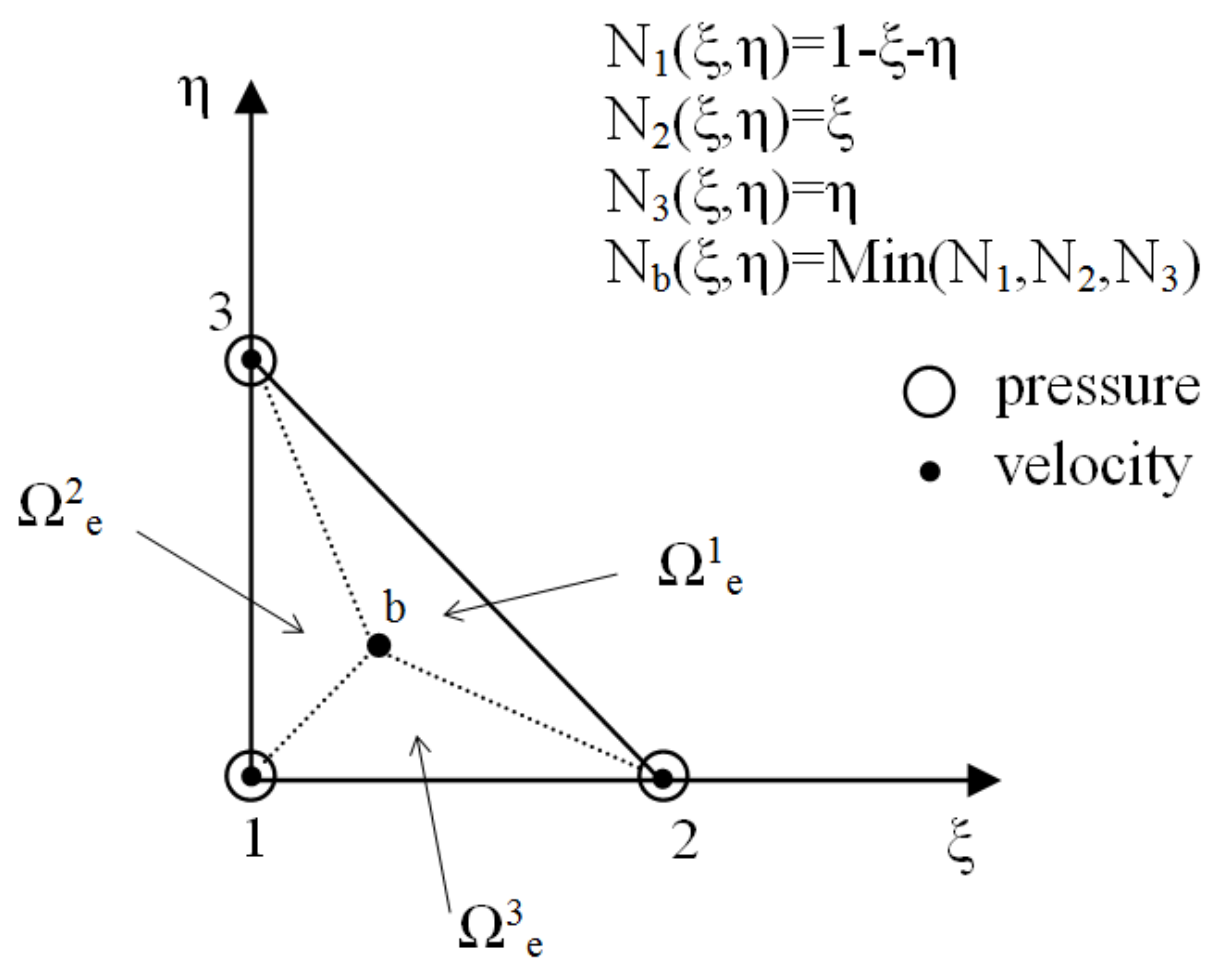


Figure 3

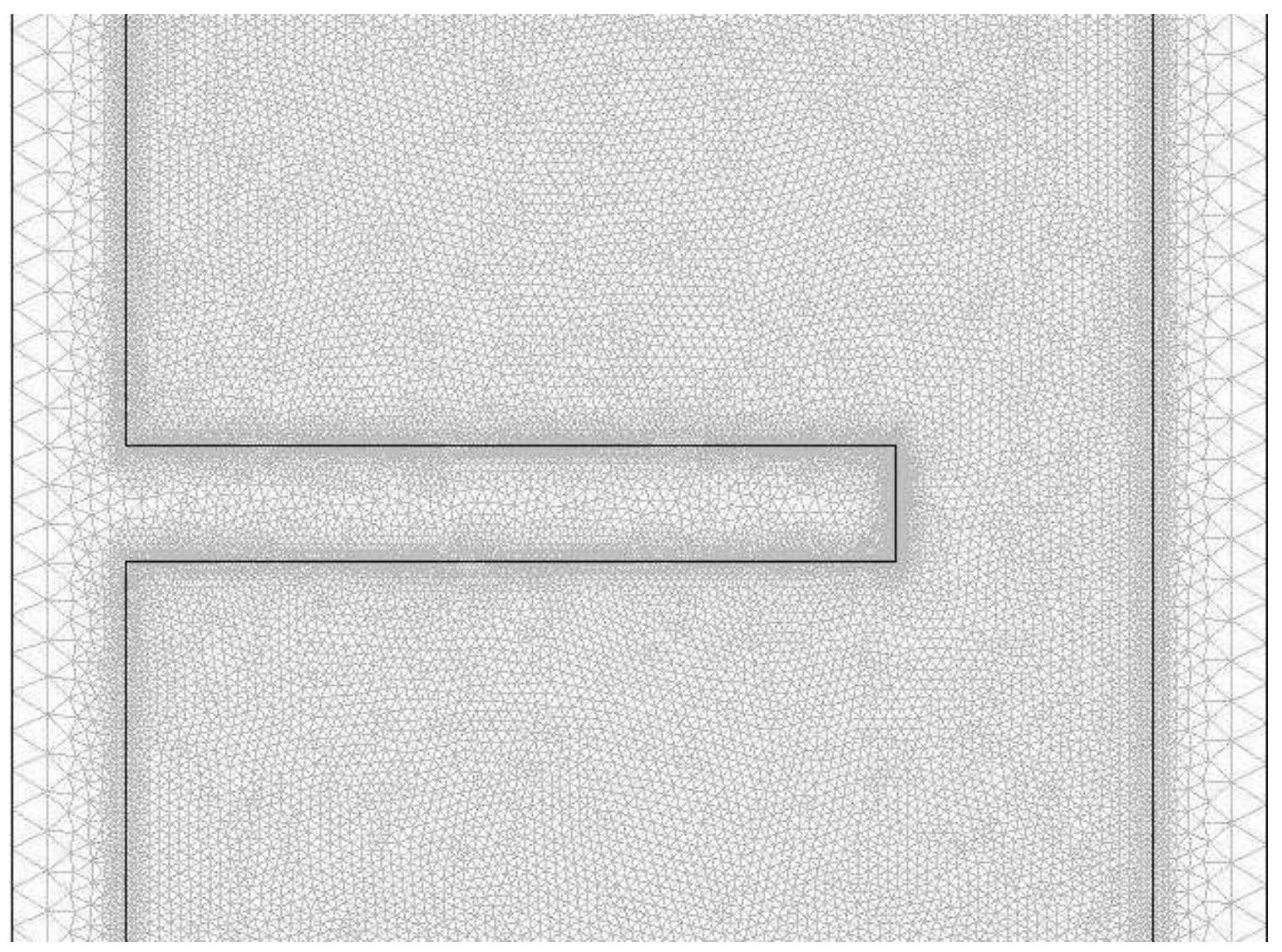



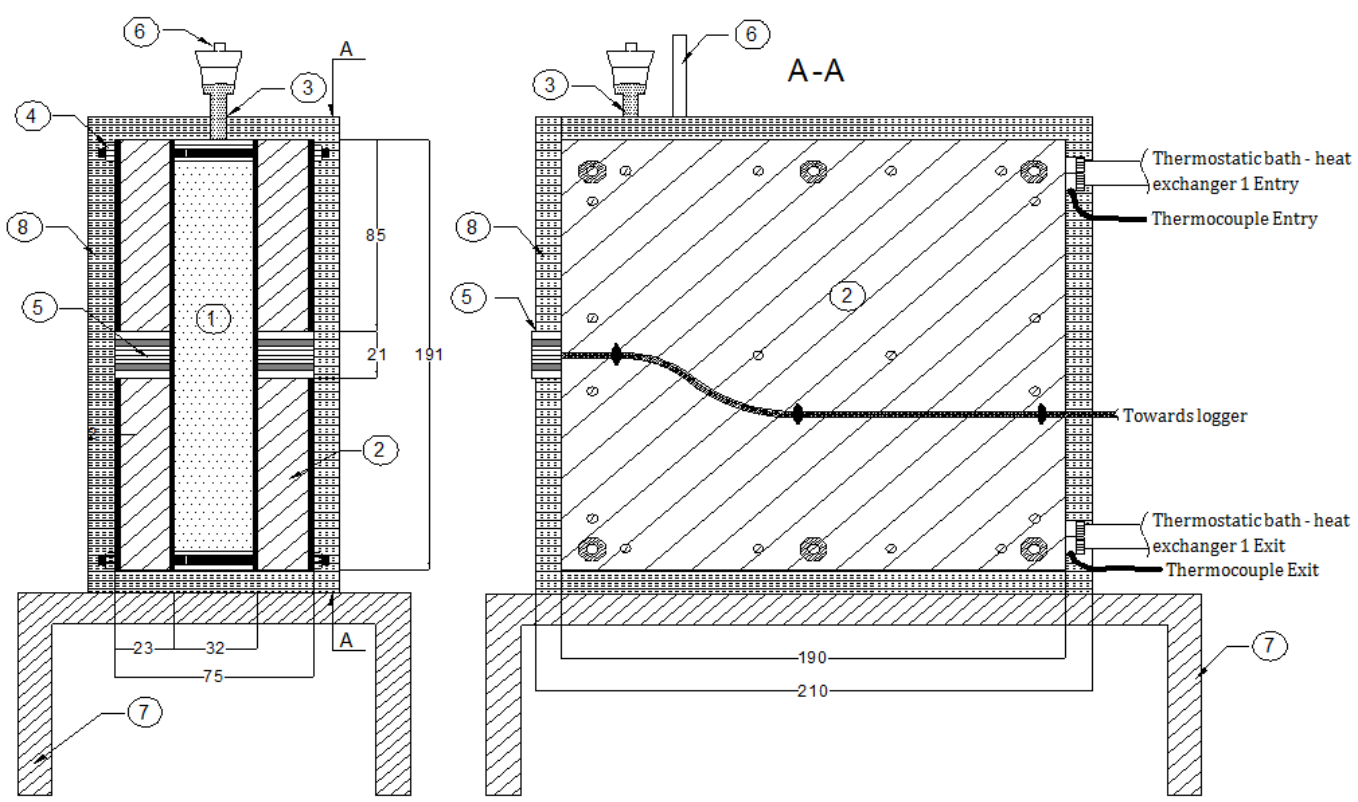
Figure 5
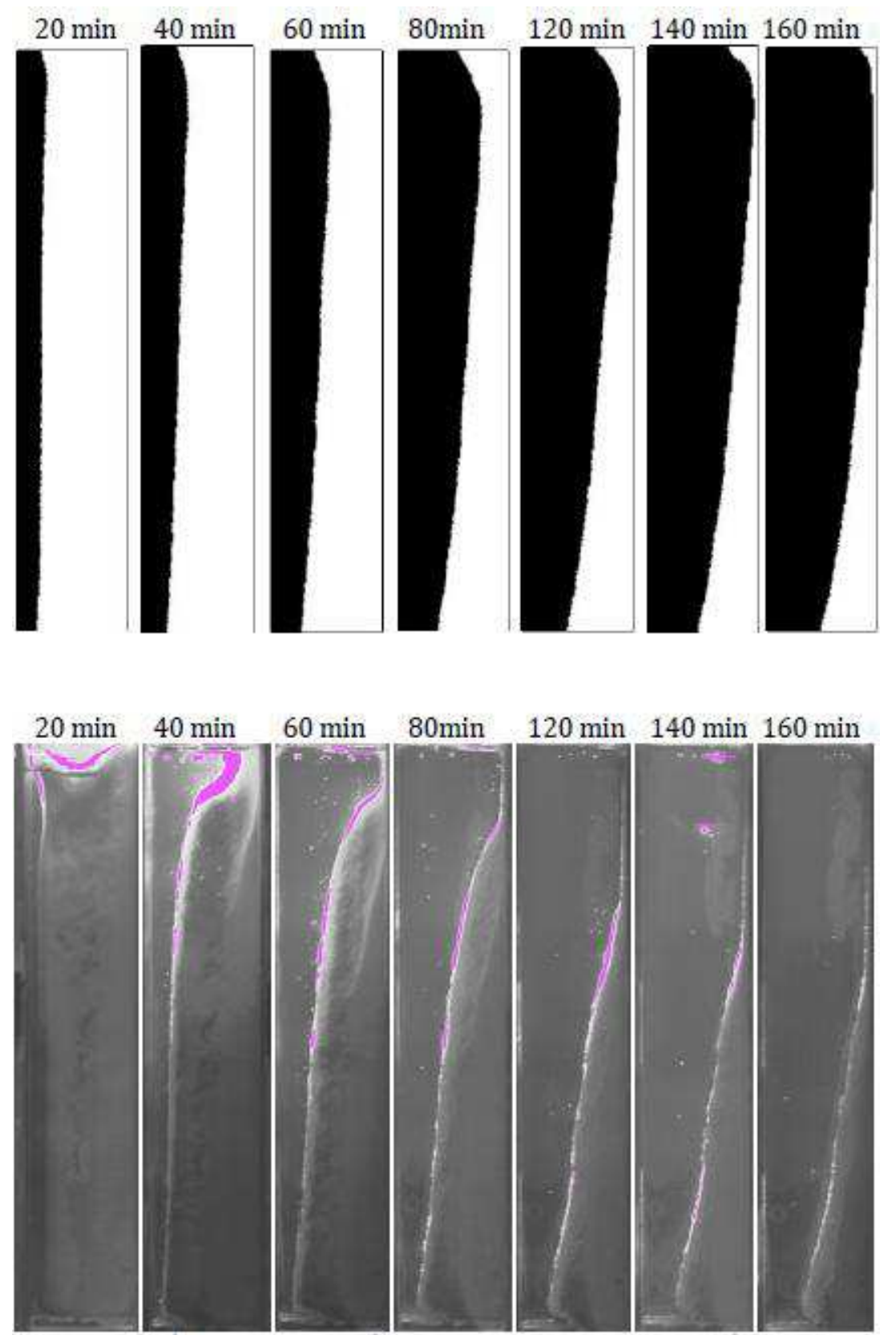


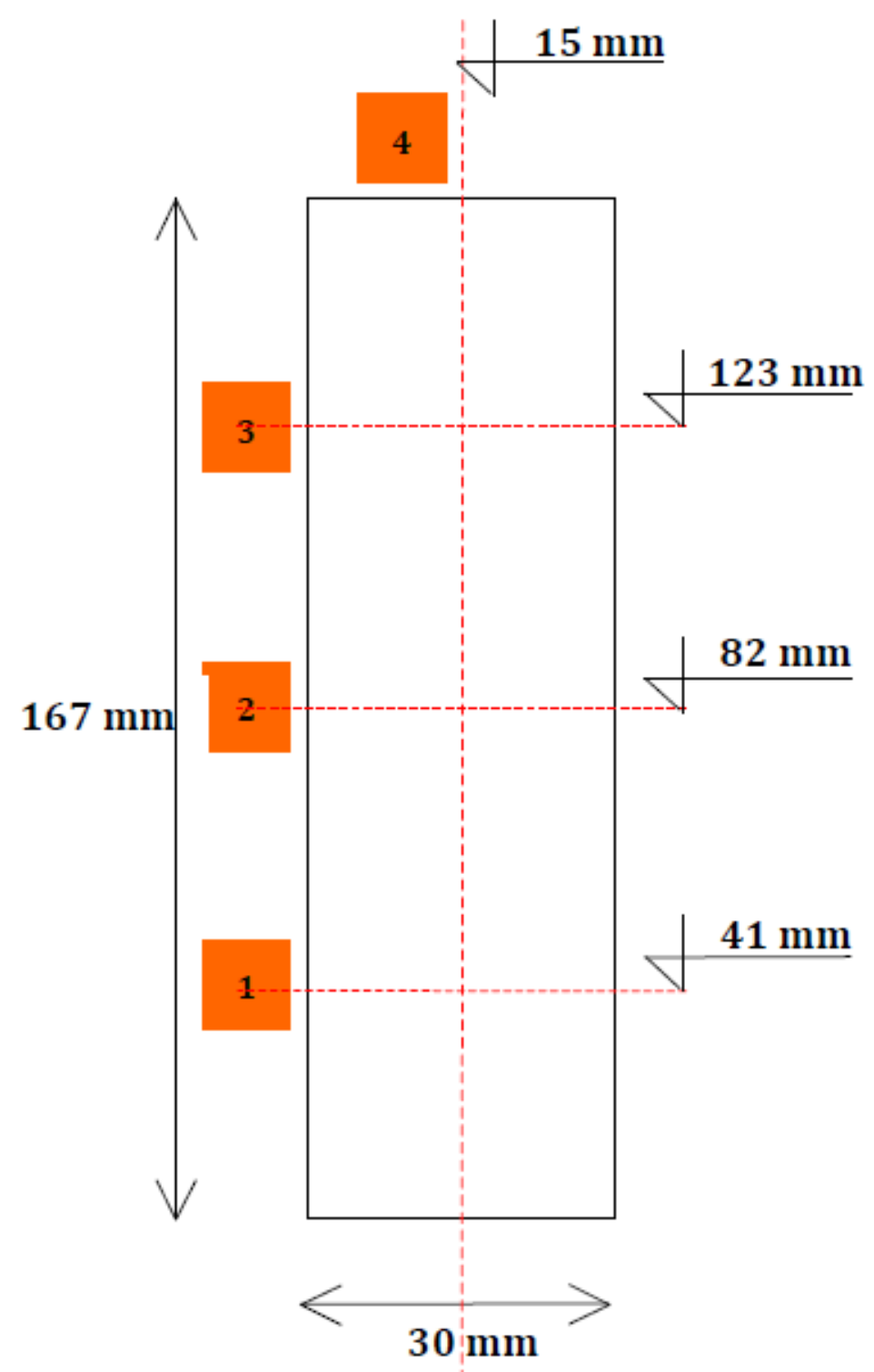


Figure 7
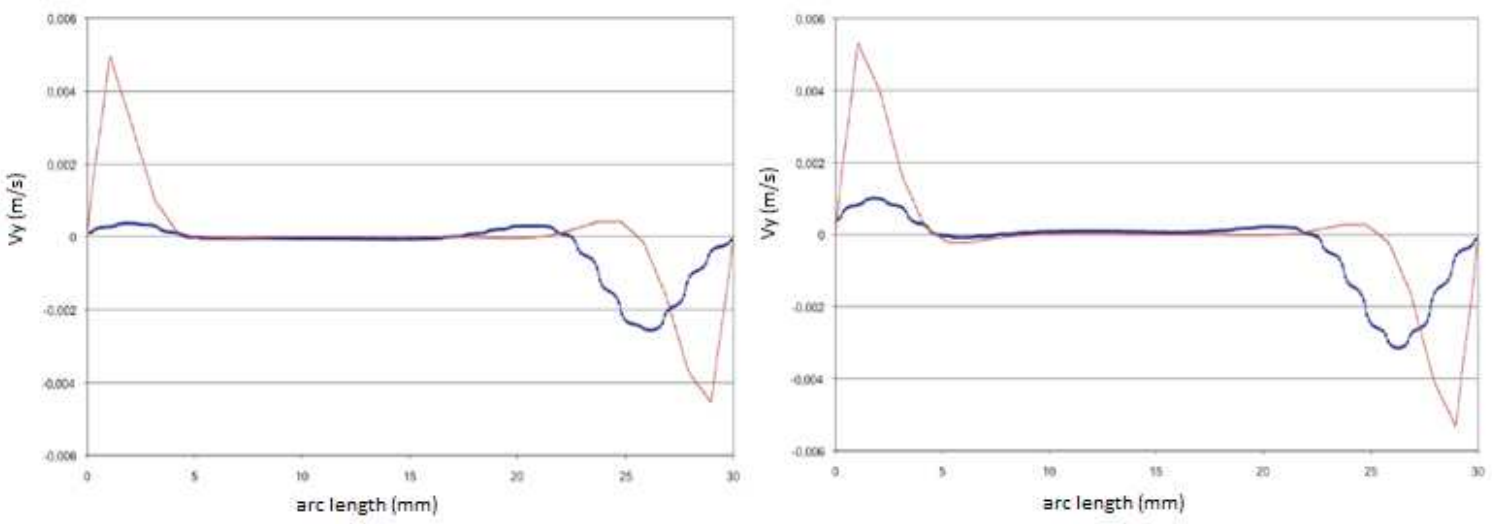

(1)

(2)|
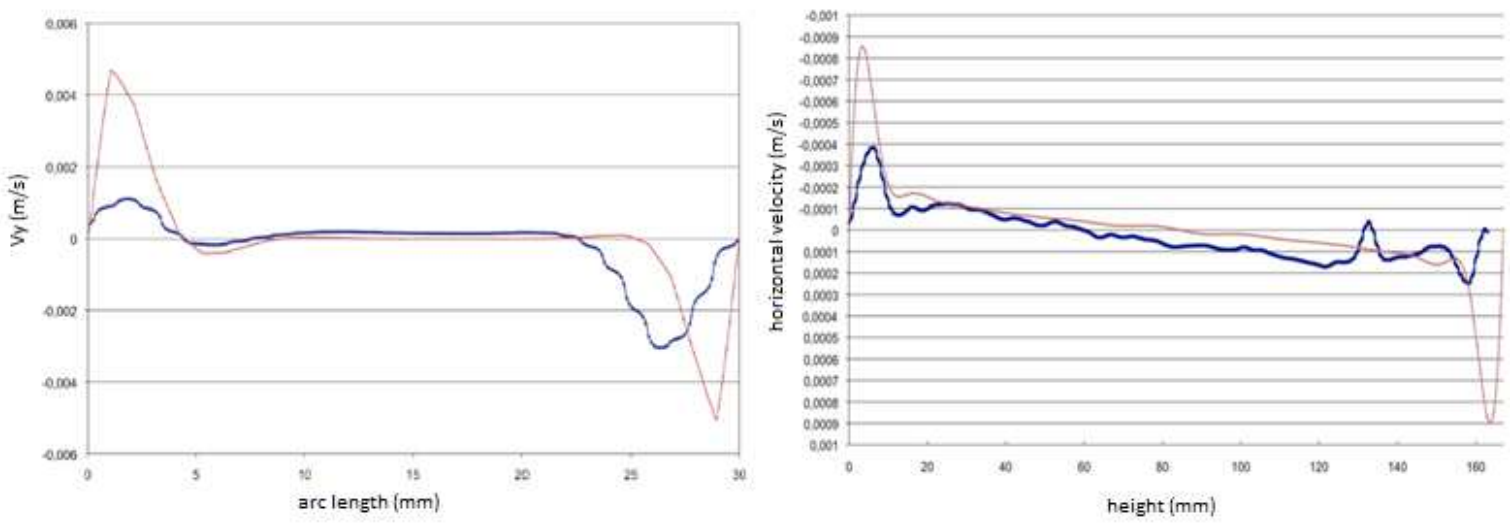

(3)

(4)

- Numerical simulation 
Figure 8

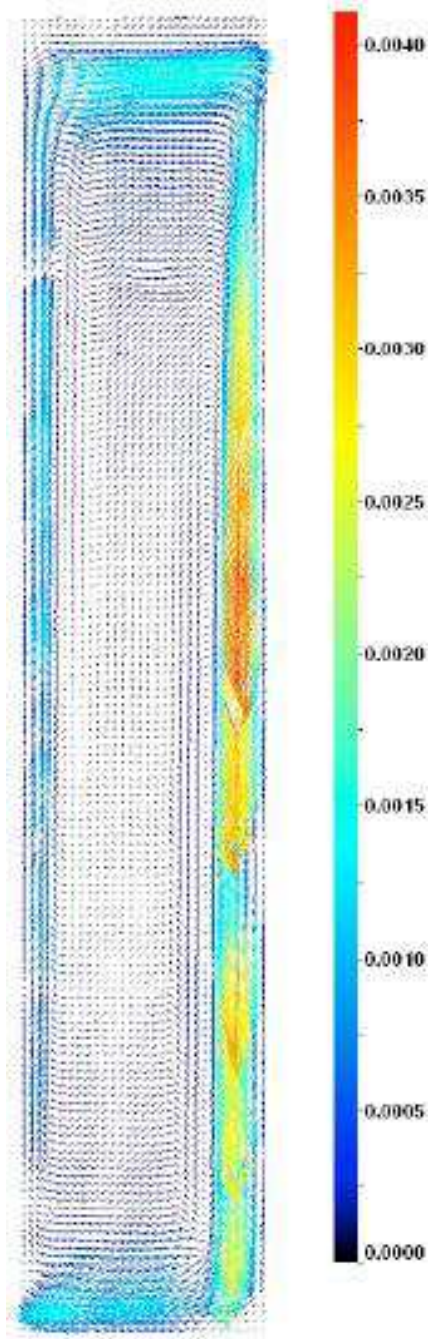


Figure 9

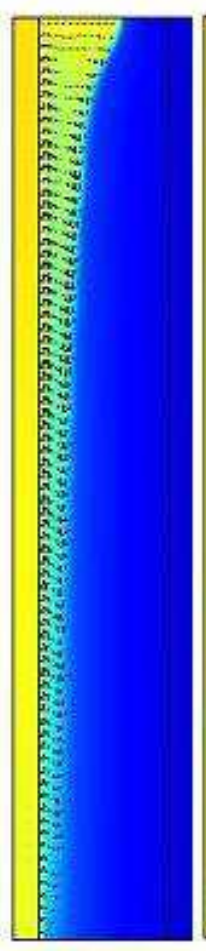

$30 \mathrm{~min}$

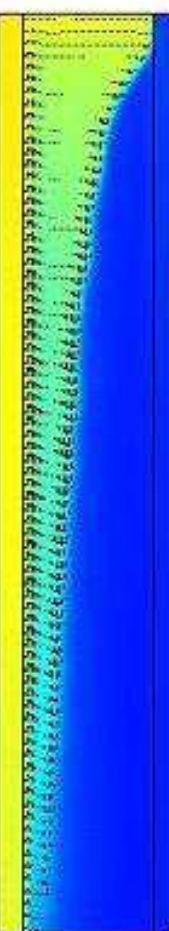

$45 \mathrm{~min}$

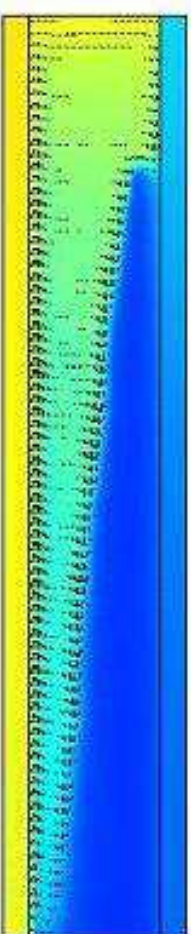

$60 \mathrm{~min}$

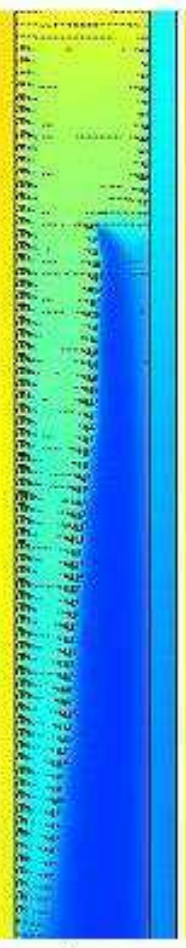

$65 \mathrm{~min}$

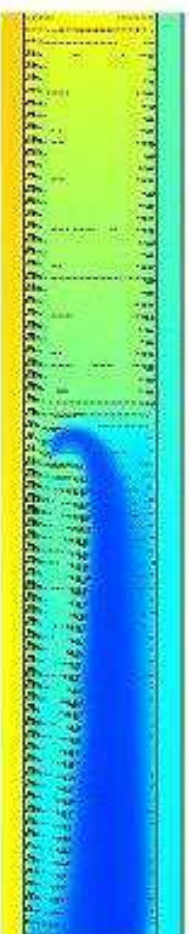

$75 \mathrm{~min}$

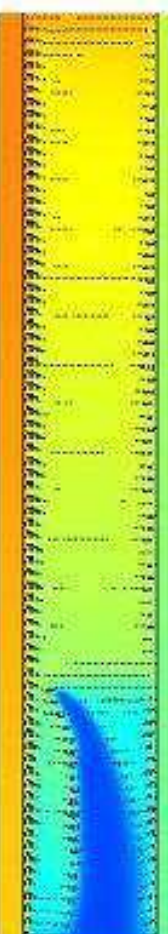

$89 \mathrm{~min} \quad 104 \mathrm{~min}$

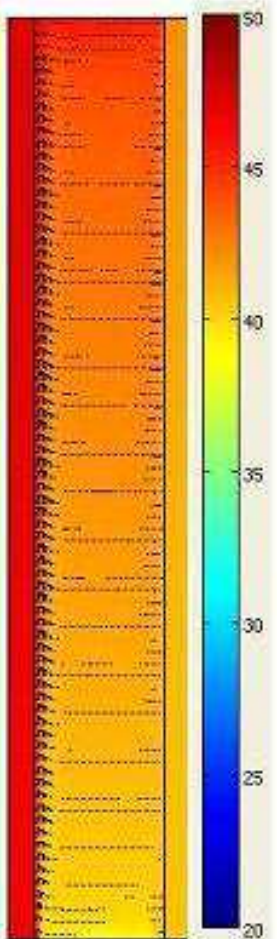


Figure 10

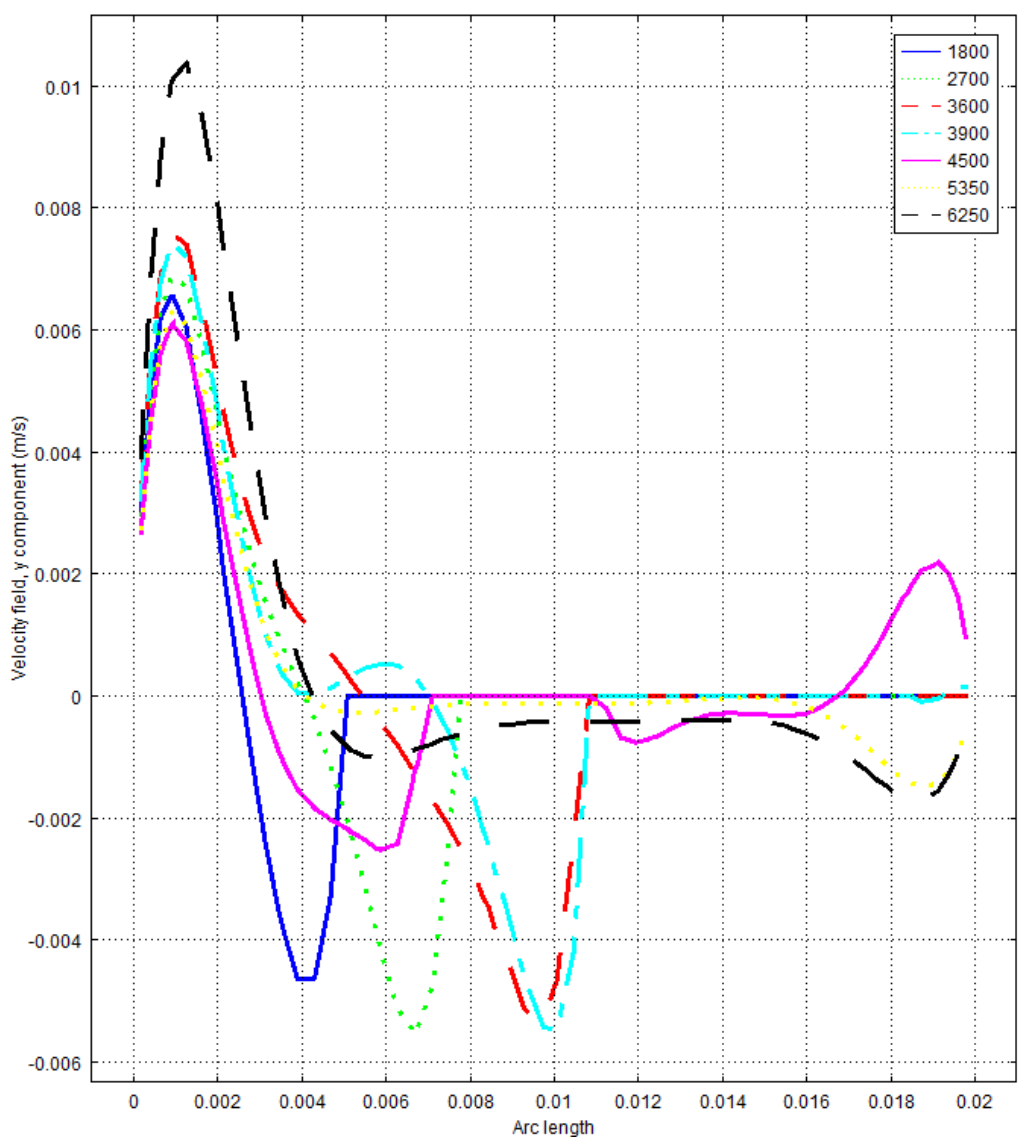


Figure 11
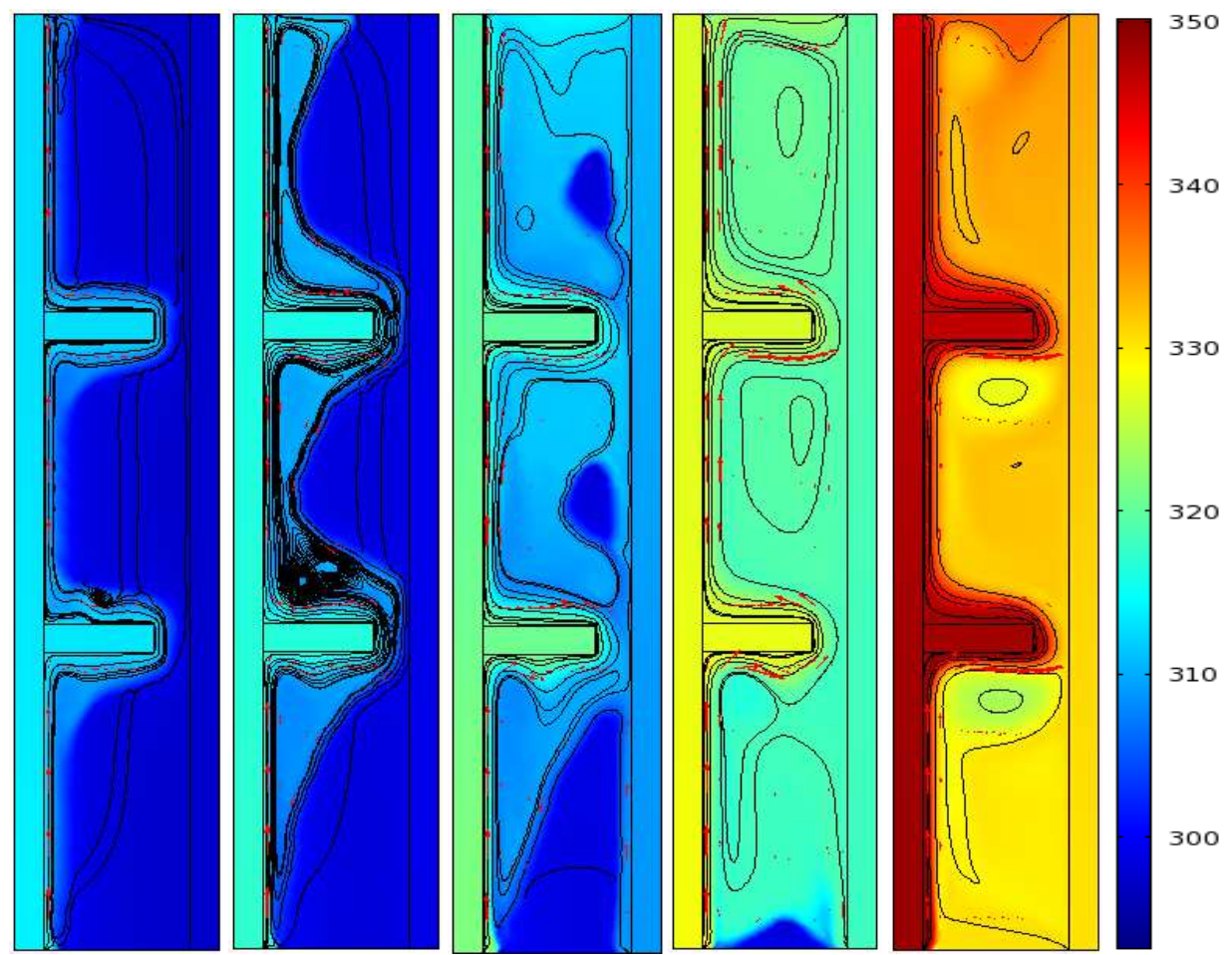

$30 \mathrm{~min}$

$45 \mathrm{~min}$

$60 \mathrm{~min}$

$75 \mathrm{~min}$

$89 \min$ 
Figure 12

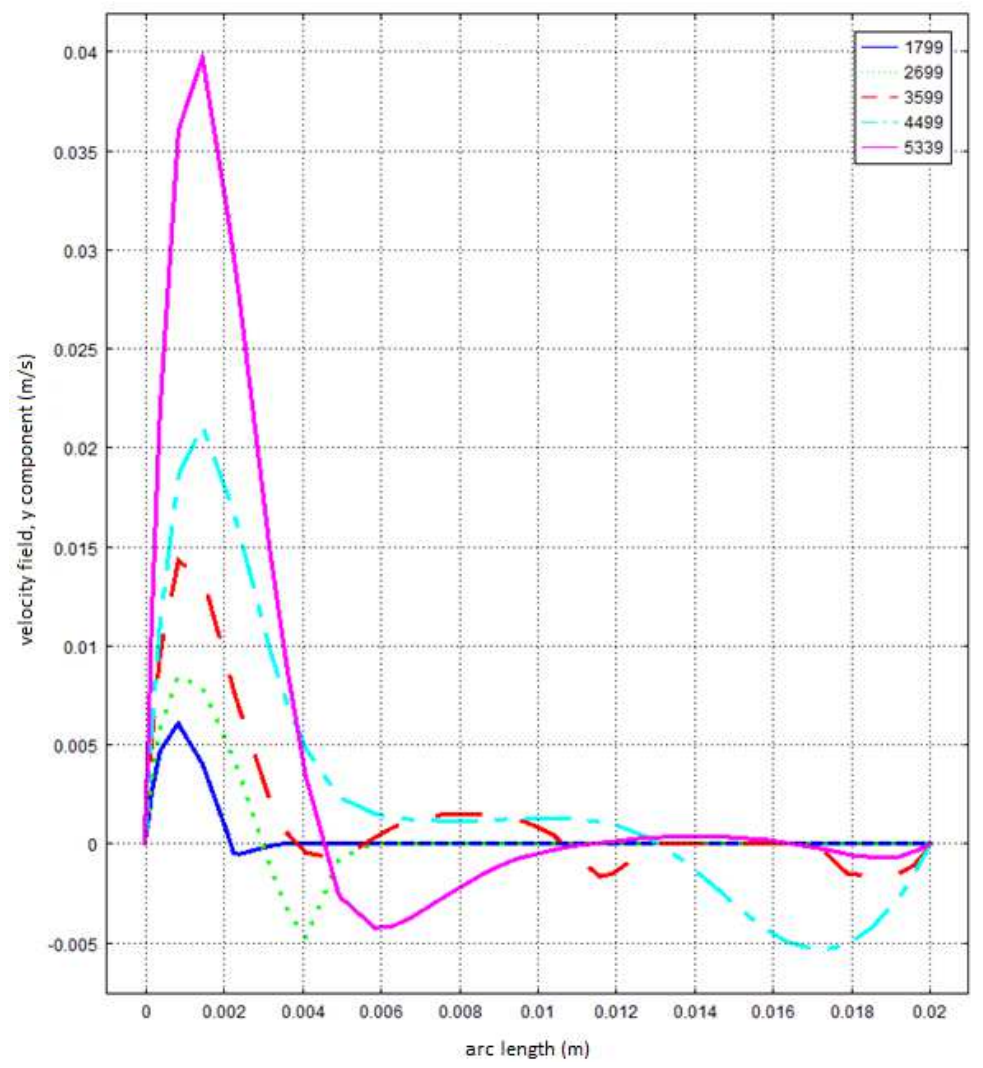


Figure 13

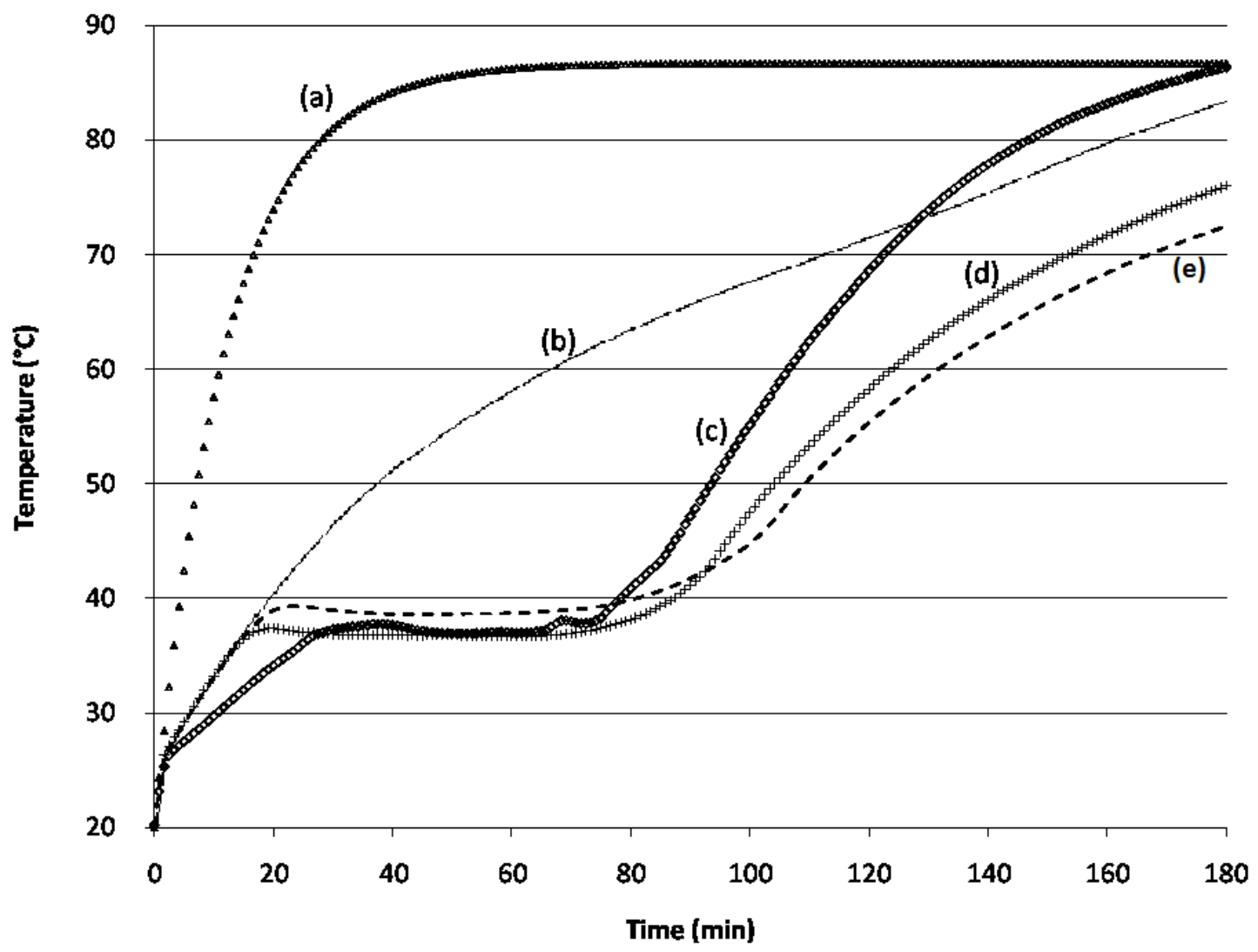

